\title{
PULMONARY HAMARTOMA
}

\author{
Lt Col HARIQBAL SINGH ${ }^{*}$, Col SK KHANNA ${ }^{+}$,
Maj VIJAY CHANDRAN ${ }^{*}$, Maj Gen RK Jetley $^{*}$
}

MJAFI 1999; 55 : 79-80

KEYWORD: Pulmonary hamartoma.

\section{Introduction}

$\mathbf{P}$ ulmonary hamartomas are benign mesenchymal tumors and represent $6 \%$ of localised solitary pulmonary nodules or coin lesions treated by thoracotomy [1]. The aim of this paper is to draw attention to this clinical entity where near definitive diagnosis can be made on imaging

\section{Case Report}

A 30-year-old asymptomatic serving soldier presented with an accidental chest roentgenogram finding of a well circumscribed coin lesion with smooth outline in right upper zone measuring 28 $\mathrm{mm}$ in diameter. Within the lesion were seen irregular flakes of calcification giving resemblance to popcom (Fig 1), a finding which is almost diagnostic on plain radiographs. CT scan revealed a 11 cll defined lobulated non enhancing mass lesion of CT valuc

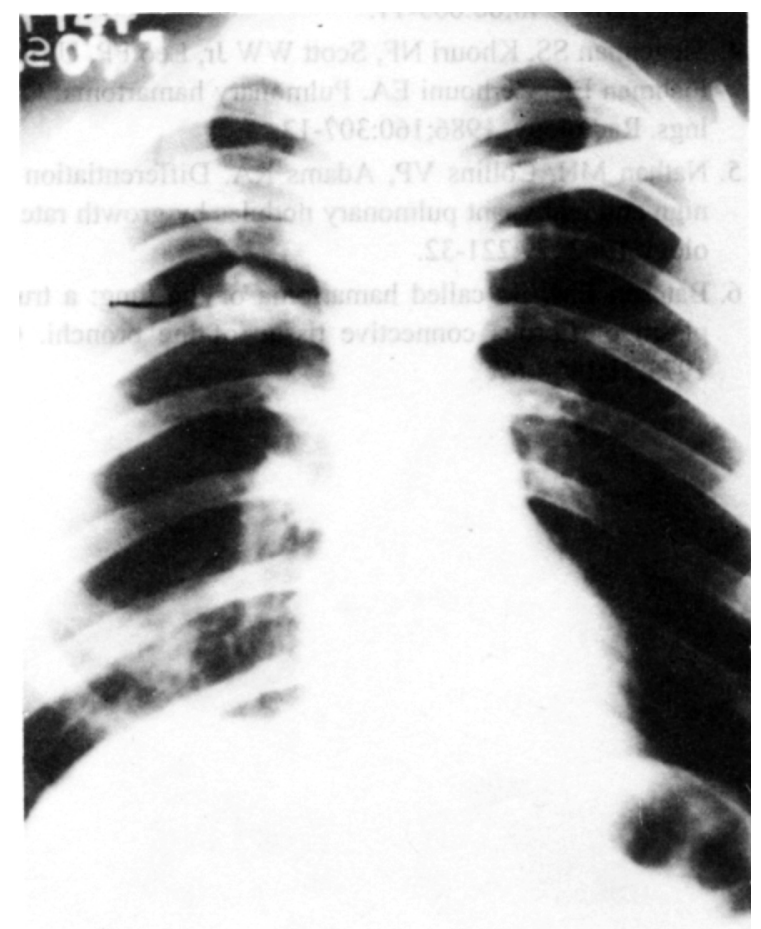

Fig. 1: Chest radiograph showing a well defined solitary pulmonary nodule with popeorn pattern of calcification in the right upper lobe.
40-65 HU measuring $25 \times 28 \mathrm{~mm}$ seen in posterior segment of right upper lobe. Multiple dense flakes of calcification ( $700 \mathrm{HU}$ ) were seen within the lesion with no surrounding parenchymal involvement. No hilar adenopathy was seen (Fig 2,3). The lesion had no fat component. The plain radiography and CT findings were almost diagnostic of pulmonary hamartoma.

\section{Discussion}

Hamartomas are benign mesenchymal tumors which have been reported in lung, liver and spleen, however, hepatosplenic hamartomas are rare. The term pulmonary hamartoma is applied to distinctive mass or coin lesion commonly found in the lung in the fifth and sixth decade with only $6 \%$ of cases seen under the age of 30 years with male preponderance of $3: 2$ [1]. It is a benign neoplasm composed of a mixture of mesenchymal and epithelial tissues. Cartilage is generally the dominant mesenchymal component. The cartilaginous matrix exhibits variable degree of calcification and ossification [2]. Fat or myxomatous con-

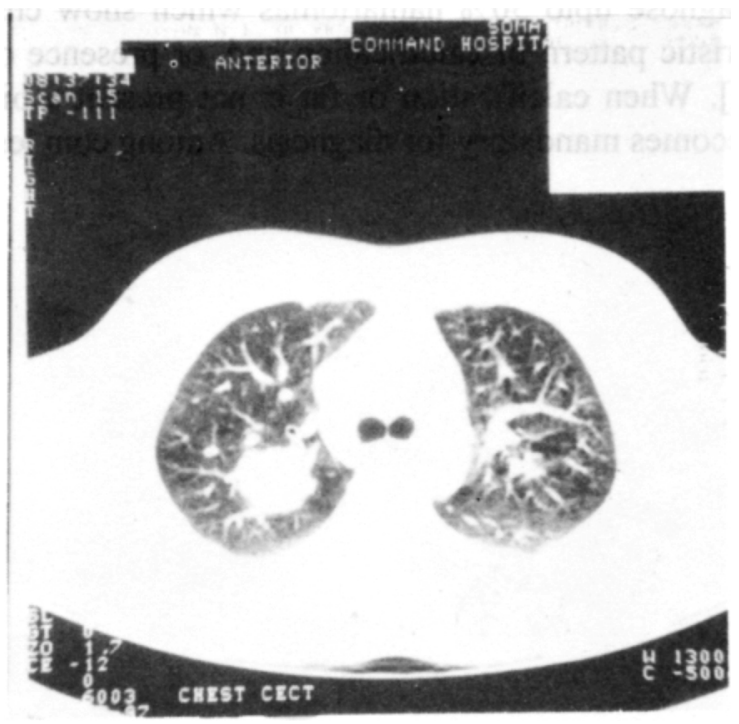

liig. 2 : $\mathrm{Cr}$ scan at the level of upper chest at lung window settings showing a solitary pulmonary nodule in the right lung with no surrounding lesions

\footnotetext{
Classified Specialist, "Senior Advisor, " " Advance Course Trainee. Department of Radiodiagnosis. Command Ilospital (Southem Command), Punc 411040 . "Addl DGMS (Army), Amy lleadquarters. New Delhi 110001.
} 


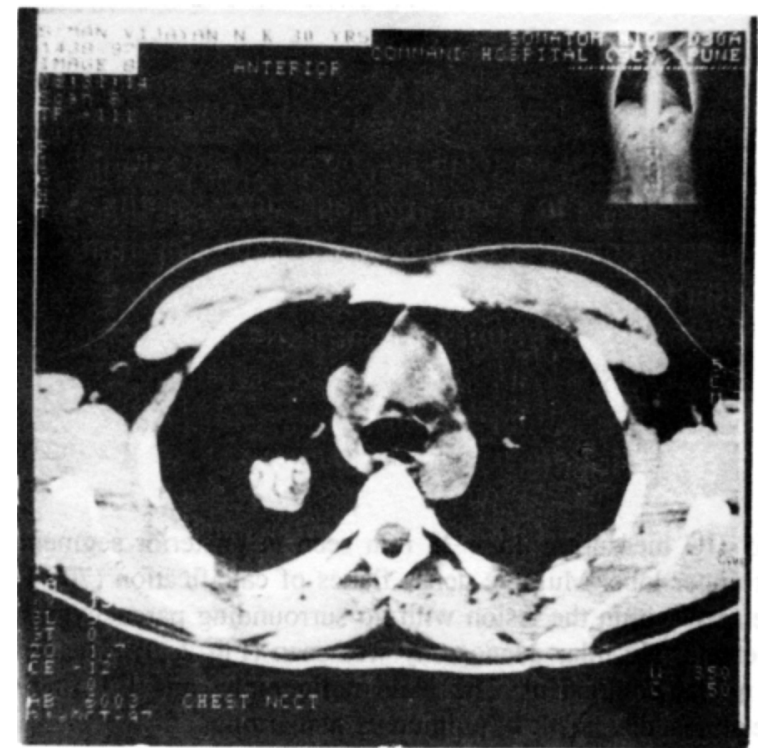

lige. 3: Cl scan at mediastinal window showing a lobulated solitary pulmonary nodule with flakes of calcilication

nective tissue is also a prominent tissue component [3]. Hamartomas are most commonly intrapulmonary, however, intrabronchial variety also exists [2]. The majority of peripheral pulmonary hamartomas produce no symptoms [3]. A pulmonary hamartoma characteristically presents on a chest radiograph as a coin lesion measuring less than $4 \mathrm{~cm}$ in diameter, nearly always well circumscribed with smooth or lobulated contours. About $30 \%$ of hamartomas show characteristic calcification on chest radiographs which often resemble popcorn as seen in our case (Fig 1). CT can diagnose upto $50 \%$ hamartomas which show characteristic pattern of calcification and, or presence of fat [4]. When calcification or fat is not present a biopsy becomes mandatory for diagnosis. Among coin lesions on serial chest radiographs pulmonary malignancies almost invariably grew rapidly with more than one doubling every 465 days, whereas benign lesions grew more slowly [5].

CT being more sensitive than chest radiograph and conventional tomography in detection of calcification and fat, detected greater number of coin lesions as hamartomas [4].

After confident diagnosis of hamartoma by $\mathrm{CT}$ in asymptomatic patients the treatment is conservative or if surgery is performed the operation is limited to segmental resection or enucleation as hamartomas have well defined capsule [6].

Coin lesions which fulfill CT criteria for hamartoma (size less than $4 \mathrm{~cm}$ in diameter, smooth margins with detectable calcification or fat) should have conservative follow up with resection reserved only for rapidly growing or symptomatic masses.

\section{REFERENCES}

I. Mandewell JE, Feigin DS. Benign tumours of the lung. Semin Roentgenol 1977;12:175-86.

2. Bateson EM. Relationship between intrapulmonary and endobronchial cartilage containing tumours (so called hamartomas). Thorax 1965;20:447-61.

3. Hall WC. Roentgenologic significance of hamartoma of the lung. AJR 1948;60:605-11.

4. Siegelman SS, Khouri NF, Scott WW Jr, Leo FP, Ulrike HM, Fishman EK, Zerhouni EA. Pulmonary hamartoma: CT findings. Radiology. 1986;160:307-12.

5. Nathan MH, Collins VP. Adams RA. Differentiation of benign and malignant pulmonary nodules by growth rate. Radiology,1962;79:221-32.

6. Bateson EM. So called hamartoma of the lung: a true neoplasm of fibrous connective tissue of the bronchi. Cancer 1973;31:1458-67. 